
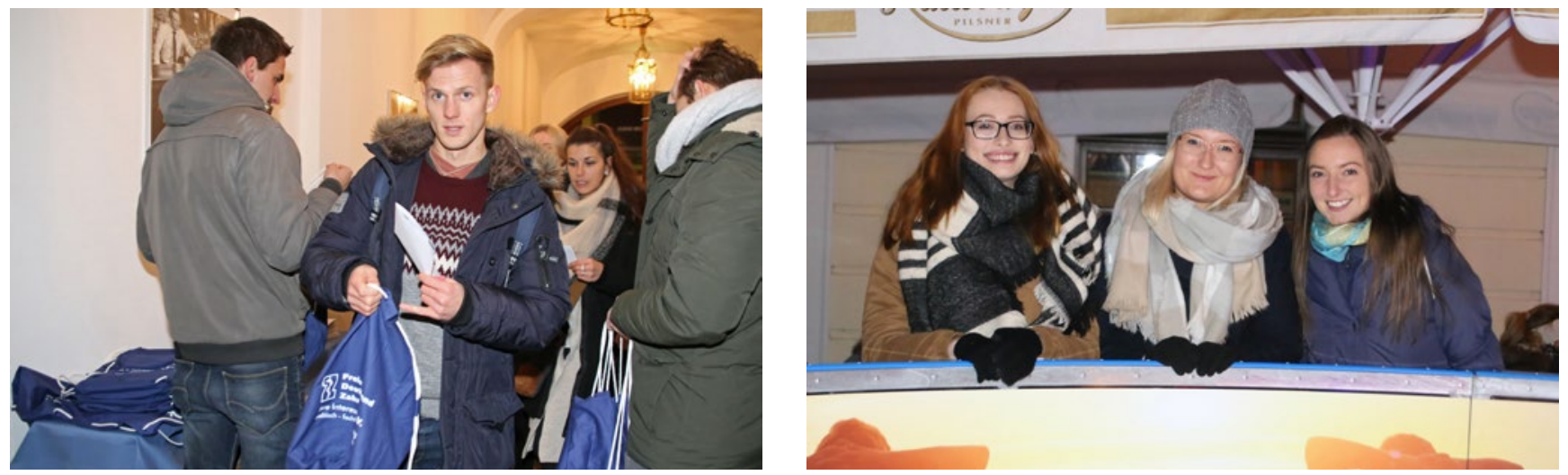

Beliebte Aktion des FVDZ-Landesverbandes Sachsen

\title{
Spaßiger Austausch auf dem Eis
}

Wenn der Freie Verband Deutscher Zahnärzte (FVDZ) in Sachsen zum Jahresende auf die Eisbahn bittet, dann überlegen die Zahnmedizinstudenten der Uni Dresden nicht lange. Denn das vorweihnachtliche Schlittschuhlaufen auf der präparierten Eisfläche des Hotels Kempinski ist unter den Kommilitonen mittlerweile lieb gewonnene Tradition. Und so kamen diesmal wieder 180 Studentinnen und Studenten, um den Abend auf Kufen zu genießen.

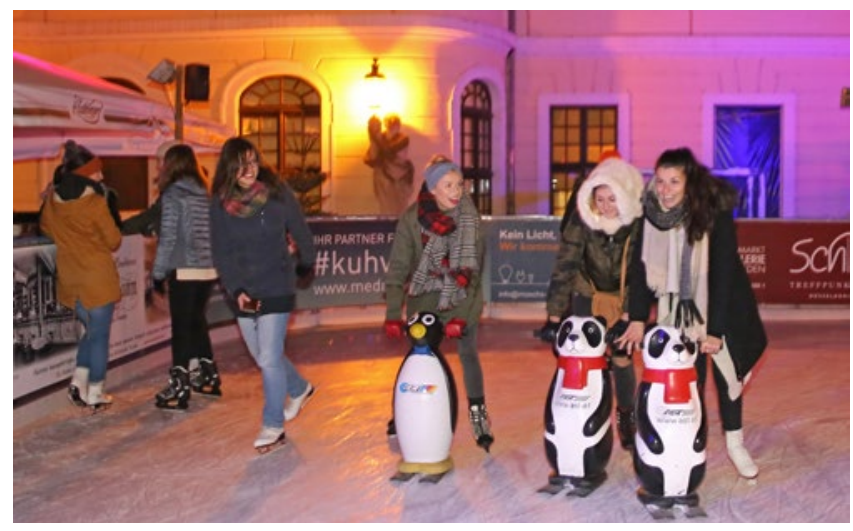

Eingeladen hatte der FVDZ-Landesverband zusammen mit der Deutschen Ärzte Finanz unter dem Motto „MediLearn für Zahnis - wie geht es weiter“. Neben dem Spaß auf Schlittschuhen standen auch zahlreiche Gespräche über den Unialltag, aber auch über die Arbeit und das Angebot des Freien Verbandes statt. Der Landesverband geht so gezielt auf den Berufsnachwuchs zu und macht sich bekannt. Mit Erfolg, wie die alljährliche Aktion zeigt.

red

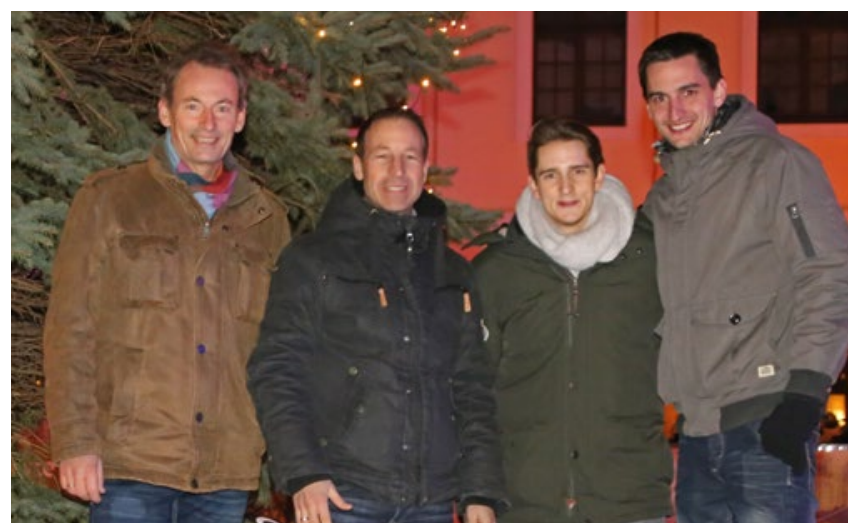

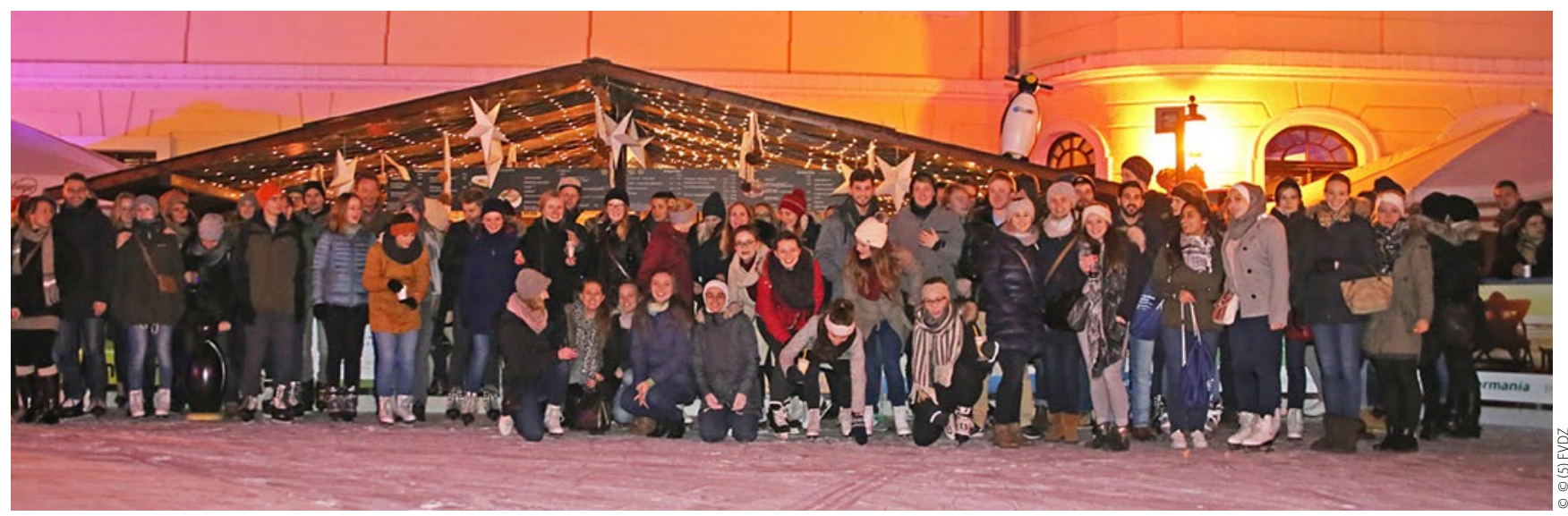

